Article

\title{
Social Learning among Transplant Sports Event Volunteers
}

\author{
Kwok Ng1 and Anna-Katriina Salmikangas ${ }^{2}$ \\ Received: 28 ${ }^{\text {th }}$ November 2017; Accepted: 19 ${ }^{\text {th }}$ June 2019; Published: $1^{\text {st }}$ July 2019
}

\begin{abstract}
Volunteering in adapted sports competitions has not been studied as much as in other competitions. Survey data from volunteers in a supportive role at the European Transplant Sport Week 2016 in Finland were analysed to report the way involvement in the event increased knowledge of transplantation. Through social learning theory, the aim of the study was to report the associations between changes in knowledge, training and volunteering experience of supportive role volunteers. A representative sample of the adult volunteers $(n=95$, Male $=35$, Female $=60$; Disabled=31, non-Disabled=64; $\mathrm{M}_{\mathrm{age}}=49.7 \mathrm{y}$ old, $\mathrm{SD}=16.8$ ) responded to a web-based survey. Questions included self-perceived knowledge of transplantation before training, after training and after the event. The data was analysed through ANOVA repeated measures to test the changes of knowledge at each phase, after adjusting for prior experience with transplantation. There were large effects from the knowledge rating (ranged from 4-10) prior to training (mean 6.04; $\mathrm{SD}=1.46$ ) to after training (mean=7.89; $\mathrm{SD}=1.01, \mathrm{~d}=1.48$ ) after the event (mean=8.82; $\mathrm{SD}=0.81, \mathrm{~d}=2.36$ ) for people with no experience with transplantation. People with experience with transplantation $(n=11)$ reported increased knowledge from training (mean=8.91, $\mathrm{SD}=0.70, \mathrm{~d}=1.31$ ), but not from between after training and after the event. As volunteers' knowledge of the organ transplant sport had increased significantly due to the volunteer training and working at the event, it can be noted that the volunteer programme was successful in terms of achieving the desired goal.
\end{abstract}

Keywords: Training; Nonformal learning; Experiential learning; Volunteering

\section{Introduction}

The majority of successful sports events rely upon the effectiveness and reliability of volunteers (Farrell, Johnston, \& Twynam, 1998; Giannoulakis, Wang, \& Gray, 2007). The cost of volunteer hours, if paid, would amount to bankruptcy of the event organisers, and sports events would not be financially feasible (Preuss, 2006). When mega-events like the Olympics always run into debt, reasons for hosting multisport events are usually not for direct financial benefits (Zimbalist, 2016). Zimbalist (2016) described other tangible gains to host of sport events such as, home advantage for their athletes, attraction of athletes to acclimatise to the environment prior to the sports event, increased tourism as a result of the events, public awareness of the sports and the athletes, as well as political reasons. Through the event's volunteers, the organisers' needs can be met (Ferrand \& Skirstad, 2015). Sports events can be one off, and recruiting people with other skills than just regular voluntary activities can be challenging (Cuskelly, Taylor, Hoye, \& Darcy, 2006). Therefore, recruitment of volunteers at events needs to be attractive.

According to the 2006 Eurobarometer survey on European Social Reality, one in six people carry out sports related voluntary activities (Mathou, 2010). In the first decade of the Millennium, nine countries in the European Union (Czechia, Denmark, Estonia, Finland, France, Ireland, Malta, the Netherlands and Spain) increased their volunteers in sports. As such, within Finland, the volunteering landscape was reported to be high compared to other European countries (Mathou, 2010; Official Statistics of Finland, 2009). Finland has one of the densest voluntary organisation cultures in Europe, with over 127,000 organisations identified in 2007, which compares with the 4,168 registered NGOs in Greece (Mathou, 2010). Despite this, large international sports events have 
difficulties to recruit enough volunteers for the event (Rantalainen \& Taskinen, 2015). In addition, once volunteers are recruited, the backgrounds of the individuals can be vast and diverse, in terms of skills, knowledge, and abilities (Cuskelly et al., 2006). Therefore, it is essential that volunteers attend training to know more about the roles during the events. There are a variety of roles that volunteers fulfil, some of them work directly with athletes at the competition sites, outside of the competition sites, such as food, accommodation and transportation, and some volunteers mainly interact with the general public (Ferrand \& Skirstad, 2015). As a result, training needs to be broad, but also specific to meet the needs of the volunteers' limited time to come to the training sessions. The organising committee must arrange and prepare training. It can be a task-intensive activity for organisers, particularly at a time, when much of the focus is on organising the logistics of the event. Volunteers that take part in events for adapted sports may require training regarding specific issues related to individuals who require activities to be adapted. For example, knowledge about working with people who have particular needs is essentially different from traditional sports event volunteering (Shiota, 2018).

Other studies in adapted physical activity that have argued for categorising terminology, for example between adapted and adaptive physical activity (Hutzler \& Hellerstein, 2016). In this paper, it is necessary to use specific terms for specific cases. Transplant sports are a form of adapted physical activity and is recognised under the Finnish Sports Association of Persons with Disabilities (FSAPD) as one of the sports for persons with disabilities it umbrellas. According to the UN convention on the rights of persons with disabilities, persons with disabilities include those "who have long-term physical, mental, intellectual or sensory impairment which in interaction with various barriers may hinder their full and effective participation in society on an equal basis with others" (United Nations, 2006). Although there are elite athletes with organ transplants, they remain in the minority of transplant recipients and most require adaptations to engage fully in society.

\section{Adaptations for transplant sports}

Approximately 50 people per Million have received some form of organ transplantation (Lund et al., 2014). Athletes who are eligible to take part in the Transplant games include people who have had organ transplants. The European Transplant Sports Week (ETSW) 2016 was held in Vantaa, Finland. It consisted of two European sports competitions, a youth camp, researchers' symposium, and sports for all events (Figure 1). Due to the multiple events, volunteers specific to sports were allocated to the sports competitions. Other support volunteers, included in this study, helped run the other events that took place during the week.

\section{Transplant Sports Week Events}

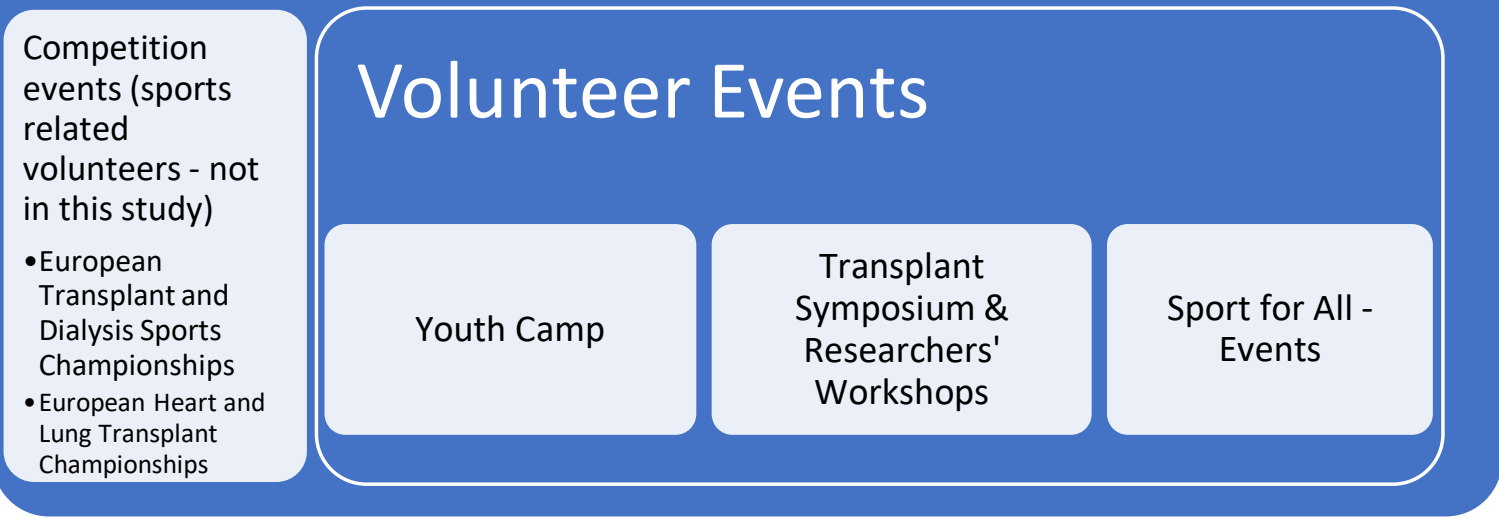

Figure 1. Overview of Volunteer Involvement in the European Transplant Sports Week 
One of the competitions was for athletes who had heart, lung, and heart-lung transplants. The other competitions were called the European Transplant and Dialysis Sports Championships. This latter competition was mainly for athletes who were kidney, liver, heart, lung, pancreas, bone marrow transplant recipients and dialysis patients. Adaptations to the competitions are common, particularly whereby transplant recipients and people on dialysis compete separately, where possible. For many transplant recipients, not all regain a normal level of physical activity (Williams \& McKenna, 2012). In addition, recipients report prominent barriers to being physically active including, health problems following transplantation, insufficient energy levels and fear of exercise (van Adrichem et al., 2016). Therefore, adaptations to physical activity also include considerations for the rate of recovery following transplantation and type of transplant.

There were four goals for the European Transplant Sports Week 2016 (Julin \& Karhu, 2016). The first goal was to enhance social inclusion of organ transplant recipients by using sports in European and national level. The second goal was to promote equal opportunities and participation in organ transplant sport on European and national level. The third goal was to bring together European transplant sport and patient associations. The fourth goal was to raise awareness of organ transplant sport and health enhancing physical activities and is the focus of this study.

\section{Theoretical Framework}

According to social learning theory, individuals learn through others (Bandura, 1969). Unlike theoretical and directive learning, where people are only informed of the knowledge, social learning places the individual in the environment to facilitate their learning (Grusec, 1992). Most sport event volunteers are recruited to help with the event environment and sources of social learning are plenty. Volunteering itself offers an opportunity to engage citizens into lifelong learning through training and hands on experience (Tufts, 2004). These activities have the potential to plant a seed of knowledge that can be developed into better understanding about diversity and social inclusion.

For the majority of sports events, volunteers have been attracted to volunteering through the possibilities of being part of a nostalgic event, to take part in friendships and to share ones' own expertise (Fairley, Kellett, \& Green, 2007). However, there are still issues concerning the awareness of adapted sports events. For example, although the Paralympic Games are scheduled in Tokyo in 2020, less than half the people in Japan surveyed, stated they were not interested in volunteering, participating, or spectating in disabled sports (Shiota, 2018). However, volunteering in adapted sports events tends to be higher among people who have family or friends taking part in the event (Khoo \& Engelhorn, 2011).

Sports events that are not televised, lack availability on social media, or reach people may be difficulty to volunteer effectively. Volunteer efficacy is based on the premise of Self-efficacy Theory and is context specific. A person with more self-efficacy has confidence in their ability to perform a specific task. In the case of volunteers, the individual believes in themselves that they can fulfil the tasks as a volunteer. According to self-efficacy theory, there are four tenants for increasing selfefficacy; mastery, verbal persuasion, vicarious experiences and physiology (Bandura, 1977). Volunteer efficacy has been considered an important construct for volunteers to complete their job satisfactorily, and to have the willingness to continue and volunteer again (Cuskelly et al., 2006). In addition to the mastery accomplishments, another important source of volunteer efficacy is verbal persuasion, or in this case the social support of others during the event. The second strongest source of volunteer efficacy is based on the past experiences, in this case, for novel volunteers, their experience would be minimized, while people who have volunteered for several events, have their ability to use the past to help inform their decisions in the present and in the future.

One main construct that fits with social learning and self-efficacy of volunteers is the change in knowledge the individual experiences following training (Klein \& Sondag, 1994). However, the effect of change in knowledge is not enough to determine if the self-efficacy has improved. Therefore, it is important to determine the change through experiences. The area of study concerning sport event volunteers and social learning theory is limited, hence, the purpose of this study was to report the 
associations between changes in knowledge, from training and volunteer experience while performing supportive volunteer tasks at the ETSW.

\section{Materials and Methods}

\section{Participants}

The ETSW consisted of sports competitions as well as non-competition events. The volunteer management of the sports competitions were run separately to the non-competition events. Recruitment of sports competition volunteers were centred around the local sports clubs, as they had the expertise to run the sports competitions. The non-competition volunteers were needed for all other tasks related to non-competition events and the bridge between the competition athletes and the competitions themselves (i.e. transport and meals). The Finnish Sports Association of Persons with Disabilities (FSAPD) organised the goalball world championships in Espoo 2014 and used the volunteer list as the first method of recruitment. FSAPD's large scope of activities includes reaching out to persons with all types of disabilities to enable activities for persons with disabilities by persons with disabilities. Open advertisements to recruit more volunteers went through social media, websites and direct communication through the transplantation organisations. All supportive role volunteers $(\mathrm{n}=182)$ from the ETSW were given an invite to complete the online survey a month after the end of the ETSW. Sports competition volunteers were excluded because they were not exposed to the training programme for non-competition volunteers. The survey was completed anonymously, and respondents had given their consent, by reading through the study protocols and proceeding to start the web-based survey. There were no consequences for none completion of the survey, thus making it voluntary. Participants could stop and withdraw at any time. At the end of the survey, there was a link to an external and an unlinked page where the respondent could include personal contact details to be entered in a raffle to win a gift voucher prize to the value of 50EUR.

The survey included demographic questions such as age, gender, educational background, and job status as grouping variables and potential confounders. Half of the volunteers $(n=95)$ completed the survey, therefore there was a response rate of $52 \%$. Demographic checks to the proportion of male to female and age groups was performed to test the representativeness of the responders to the entire volunteer population. There were equal weightings, and therefore was assumed to be representative.

\section{Training}

The local organizing committee put a higher priority on training volunteers and all its' members played their part in the training process. Experts in the area of working with volunteers in disabled sports and sports events met together to decide on the content. The content was based on previous event volunteer training material and augmented with information specific to athletes with transplantation. The volunteer manager, employed from the FSAPD, was the tutor for the training. There were five organised volunteer training sessions, which lasted three hours (Table 1). The first training session was arranged in April and the last one was just before the event in July. All the sessions had a similar programme and the content was more detailed as the closer the event came.

One main task of the FSAPD, who was the main organizer of ETSW, was to deliver information about transplantation and organ donation. Therefore, one content of the training was to give information about issues which are important to know and consider while working with athletes who have transplant or who need dialysis. All the trainings included a program which aimed to create a good volunteer community through the creation of a positive atmosphere and social functioning. Other contents of the training are included in Table 1 and were grouped into the ETSW, its organizers and collaborators, role of the volunteers, safety issues, how to become an organ donator and create a volunteer community. Volunteers were assigned to certain main roles. Due to the lack of time for training, volunteers assigned to certain roles attended specialised training. For example, a volunteer whose main role was to provide transport attended specific training about routes to and from places and other logistics needed for that role. 
In addition to the organised training sessions, a handbook for the volunteers was available in electronic and printed formats. The handbook was 48 pages with overall information about the event, contact numbers and specific information for the volunteers. A Facebook page with specific access for volunteers was used as a communication platform. The Facebook page was a form of nonformal learning, whereby volunteers may post questions and comments for other users to see and get into discussions about the event was created to deliver materials. The page was moderated by the volunteer manager, who granted access to the researchers. The Facebook page became a source of volunteer information updates and a place where volunteers could get to know each other as well as to link people with each other to benefit from shared transportation.

\section{Questionnaire}

The questionnaire consisted of basic demographic items, including sex, age, Transplant experience, prior sport volunteer experience, current disability status, educational background as well as current employment status. The generic items (sex, age, educational background, employment status) were repeated from the Finnish social sciences data archive (http://www.fsd.uta.fi/en/) templates. Dichotomous (yes or no) items were presented for experience with transplant (Have you some experience with working with Transplant recipients?), and current disability status (Do you have a disability or long-term illness?). Prior experience of sports volunteering was determined by a question about volunteering (When was the last time you volunteered in the following?), with a frequency response consisting of, "never", "last month", "2-3 months ago", "4-6 months ago", "7-12 months ago", "over a year ago". The following activities included, "sport club activities", and "sports events". Respondents who reported any experience were group as 'experienced', and responses of "never", the non-experienced.

Three single item questions were used to determine knowledge about transplant sports. Respondents were asked to provide a rating from 4-10 about their own knowledge of transplant sports, i) before recruitment, ii) after training and before the event, iii) after the sports week. This scale is a typical rating system that is synonymous with Finnish citizens as it is used to assess grading at all levels throughout school years, with 4 representing fail and 10 is excellent (Finnish National Agency for Education, 2018). Therefore, the reliability of the item has not been tested, but assumed to be strong due to the innate nature of the assessment scale and that all volunteers in this study were Finnish citizens.

Registers of volunteers' attendance for training were stored by the organisers. Personal information was decoded, and raw data was used to incorporate into the analyses. There were two items in the survey concerning the attendance of training. One item asked the participants if they have taken part in other training than the generic courses (Did you take part in other training sessions?), with response options of 'yes' or 'no'. The other item, also a 'yes' or 'no' questions, asked whether the participant had read the volunteer manual or not (Did you read the handbook before the event?).

\section{Statistical methods}

Data were analysed first through descriptive statistics, including normality tests to provide an overview of the population. To examine possible confounders, independent $t$-tests were conducted to compare the differences between gender (female vs male), age (over 50 vs under 50), and educational level (high school or lower vs vocational or higher education). A lack of statistical significance led to removal from the final statistical models. Mann-Whitney U-test was performed to test the differences in perceived knowledge ratings amongst respondents who were and were not organ donors. Repeated measures linear models were performed with three within-subjects variables as Factor 1. Variable 1 was the rating before the ETSW training, Variable 2 was after the training and Variable 3 was after the ETSW event. Prior experience with transplantation, as a donor was entered as a fixed factor into the model of the changes of perceived knowledge. Effect sizes were calculated and interpreted as recommended by Cohen and Cohen (Cohen \& Cohen, 1975). Statistical significance was considered when $\mathrm{p}<.05$ from IBM SPSS Statistics for Windows, Version 24.0. 
Table 1. European Transplant Sports Week Generic Volunteer Training Content

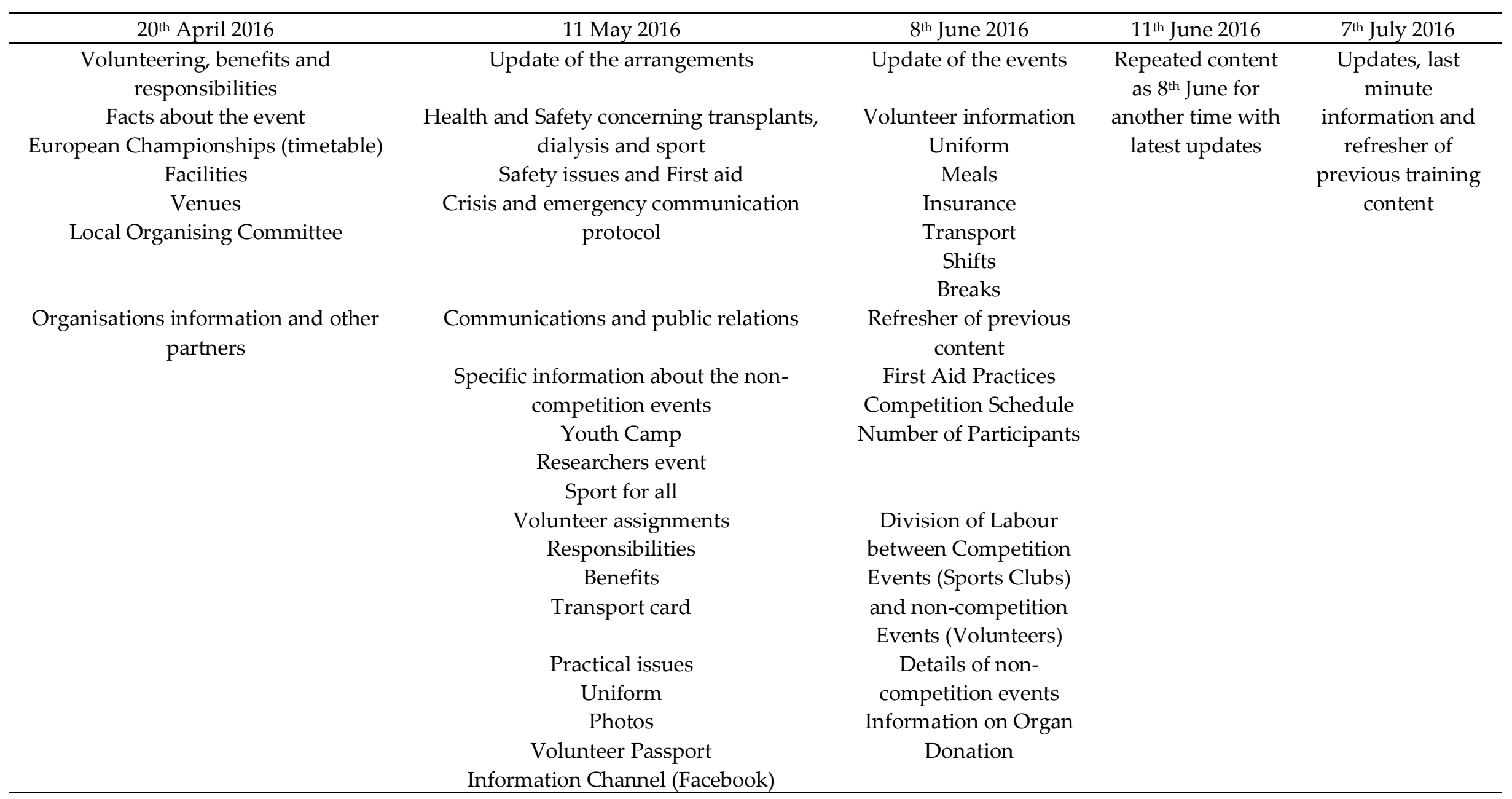




\section{Results}

\section{Study participants}

Almost two-thirds of volunteers (63\%) were female and the remaining 37\% were male (Table 2). The average age of the volunteers was 49.7 years $(\mathrm{SD}=16.8)$, with a third $(33 \%)$ of volunteers reported to be retired from work and just under a half (46\%) still working. The majority $(81 \%)$ of volunteers lived in the Metropol area consisting of Helsinki, Espoo, Vantaa and the other Uusimaa region. Few volunteers (12\%) had experience with transplantation and were organ transplant donors and half (52\%) of volunteers had some experience in volunteering in sports. A third of volunteers (33\%) reported to have a long-term illness or disability.

Table 2. Respondents with and without experience with Transplantation

\begin{tabular}{|c|c|c|c|c|c|c|c|}
\hline & \multicolumn{2}{|c|}{ Tx experience } & \multicolumn{2}{|c|}{ No Tx Experience } & \multicolumn{2}{|r|}{ Total } & \multirow{2}{*}{$\begin{array}{c}\chi^{2} \text { tes } \\
p\end{array}$} \\
\hline & $\mathrm{N}$ & Column \% & $\mathrm{N}$ & Column \% & $\mathrm{N}$ & Column \% & \\
\hline Gender & & & & & & & 0.172 \\
\hline female & 9 & 81.8 & 51 & 60.7 & 60 & 63.2 & \\
\hline male & 2 & 18.2 & 33 & 39.3 & 35 & 36.8 & \\
\hline Age & & & & & & & 0.463 \\
\hline under 50 & 6 & 54.5 & 36 & 42.9 & 42 & 44.2 & \\
\hline 50 and over & 5 & 45.5 & 48 & 57.1 & 53 & 55.8 & \\
\hline Residence & & & & & & & 0.454 \\
\hline metro & 8 & 72.7 & 69 & 82.1 & 77 & 81.1 & \\
\hline other & 3 & 27.3 & 15 & 17.9 & 18 & 18.9 & \\
\hline Education & & & & & & & 0.213 \\
\hline $\begin{array}{l}\text { high school or } \\
\text { lower }\end{array}$ & 1 & 9.1 & 22 & 26.2 & 23 & 24.2 & \\
\hline $\begin{array}{l}\text { vocational or } \\
\text { higher }\end{array}$ & 10 & 90.9 & 62 & 73.8 & 72 & 75.8 & \\
\hline Job Status & & & & & & & 0.493 \\
\hline employed & 6 & 54.5 & 37 & 44.0 & 43 & 45.3 & \\
\hline student & 0 & 0.0 & 15 & 17.9 & 15 & 15.8 & \\
\hline retired & 4 & 36.4 & 27 & 32.1 & 31 & 32.6 & \\
\hline unemployed & 1 & 9.1 & 5 & 6.0 & 6 & 6.3 & \\
\hline Sport volunteering & & & & & & & 0.596 \\
\hline no experience & 2 & 18.2 & 21 & 25.0 & 23 & 24.2 & \\
\hline club or event & 4 & 36.4 & 19 & 22.6 & 23 & 24.2 & \\
\hline club and event & 5 & 45.5 & 44 & 52.4 & 49 & 51.6 & \\
\hline Disability status & & & & & & & 0.687 \\
\hline disabled & 3 & 27.3 & 28 & 33.3 & 31 & 32.6 & \\
\hline not disabled & 8 & 72.7 & 56 & 66.7 & 64 & 67.4 & \\
\hline
\end{tabular}

Tx $=$ Transplant

\section{Training attendance and adherence}

More than half of volunteers participated in up to three training courses and $44 \%$ attended four or more training courses (Table 3$)$. Three quarters of the volunteers $(76 \%)$ reported attendance during the last training session in July. Over a quarter (28\%) of the respondents reported they participated in the other training courses that supplemented the generic training. The majority (92\%) of volunteers reported to have read the volunteers' manual prior to the event. 
Table 3. Attendance of Volunteer Training Sessions for European Transplant Sports Week

\begin{tabular}{ccccccc}
\hline & \multicolumn{2}{c}{ Tx experience } & \multicolumn{2}{c}{ No Tx experience } & Total \\
Training Frequency & $\mathrm{N}$ & Column $\%$ & $\mathrm{~N}$ & Column $\%$ & $\mathrm{~N}$ & Column $\%$ \\
\hline none & 1 & 9.1 & 2 & 2.4 & 3 & 3.2 \\
one & 1 & 9.1 & 9 & 10.7 & 10 & 10.5 \\
two & 2 & 18.2 & 16 & 19.0 & 18 & 18.9 \\
three & 2 & 18.2 & 20 & 23.8 & 22 & 23.2 \\
four & 4 & 36.3 & 21 & 25.0 & 25 & 26.3 \\
five & 1 & 9.1 & 16 & 19.1 & 17 & 17.9 \\
\hline
\end{tabular}

$\mathrm{Tx}=$ Transplant

\section{Self-evaluation of transplant knowledge}

The mean rating of knowledge prior to training or volunteering experience, from a scale of 4 to 10 , with 10 being the highest, was 6.19 (SD=1.52) (Table 4). The rating had increased to $8.01(\mathrm{SD}=1.03)$ following the attendance to training. Two-thirds (66\%) of the volunteers reported a positive shift in knowledge by 1-2 points. The mean rating from post event was highest at $8.83(\mathrm{SD}=0.81)$ at the end of the event. Over half $(55 \%)$ of the respondents' knowledge had risen by at least three points and $38 \%$ by $1-2$ points. There was an overall shift in the level of knowledge after training ( $\mathrm{p}<.001)$ with large Cohen's D effect size. In addition, there were even more improved perceptions of knowledge after the event $(p<.001)$ with a large effect size.

Table 4. Mean, standard deviation and Cohen's D of transplantation knowledge rating points

\begin{tabular}{ccccc}
\hline & & Before $^{\mathrm{a}}$ & Training $^{\mathrm{b}}$ & Event $^{\mathrm{c}}$ \\
\hline Experience & Mean & 7.36 & 8.91 & 8.91 \\
& SD & 1.50 & 0.70 & 0.83 \\
& Cohens D D-a $^{\mathrm{b}}$ & & 1.31 & \\
& Cohens D D-b $^{\mathrm{c}}$ & & & 0.00 \\
& Cohens D D-a $^{\mathrm{c}}$ & & & 1.27 \\
& Mean & 6.04 & 7.89 & 8.82 \\
& SD & 1.46 & 1.00 & 0.91 \\
& Cohens D D-a & & 1.48 & \\
& Cohens D D-b & & & 1.02 \\
& Cohens D D-a & & & 2.36 \\
\hline
\end{tabular}

Mauchly's test indicated that the assumption of sphericity had been violated for the main effect of knowledge, $\chi 2(2)=52.64, p<.001$. Therefore, degrees of freedom were corrected using Greenhouse-Geisser estimates of sphericity $(\varepsilon=.70)$. There was a significant main effect of changes in knowledge, $\mathrm{F}(1.39,129.55)=6.392$ after adjusting with prior experience with transplantation (Figure 2). More specifically, the contrast between volunteers with prior experience of transplantation and no prior experience was significantly larger before training $(\mathrm{t}=2.83, \mathrm{p}<.001)$, after training $(\mathrm{t}=3.24, \mathrm{p}=.002)$, but not after the event $(\mathrm{t}=.337$, $\mathrm{p}=.74)$.

\section{Discussion}

The main results from this study support the notion of various social learning theories (Klein \& Sondag, 1994) for volunteer experiences. The volunteers in this study felt they improved their knowledge about transplant sports from the training sessions prior to the sports week. However, more perceived knowledge was gained through actual experience of volunteering at the ETSW. The combined gain in knowledge was a combination of the formal training, as well as the non-formal training that included, experience with working with transplant recipients, reading the volunteer handbook prior to the event, and potentially the interaction with the volunteer community throughout the week. The main demographics for this study included people over the age of 50 and mainly female. In contrast to previous research that indicated most of the large sports events volunteers have been young people, for example in athletics (Itkonen, Ilmanen, Lämsä, Matilainen, \& 


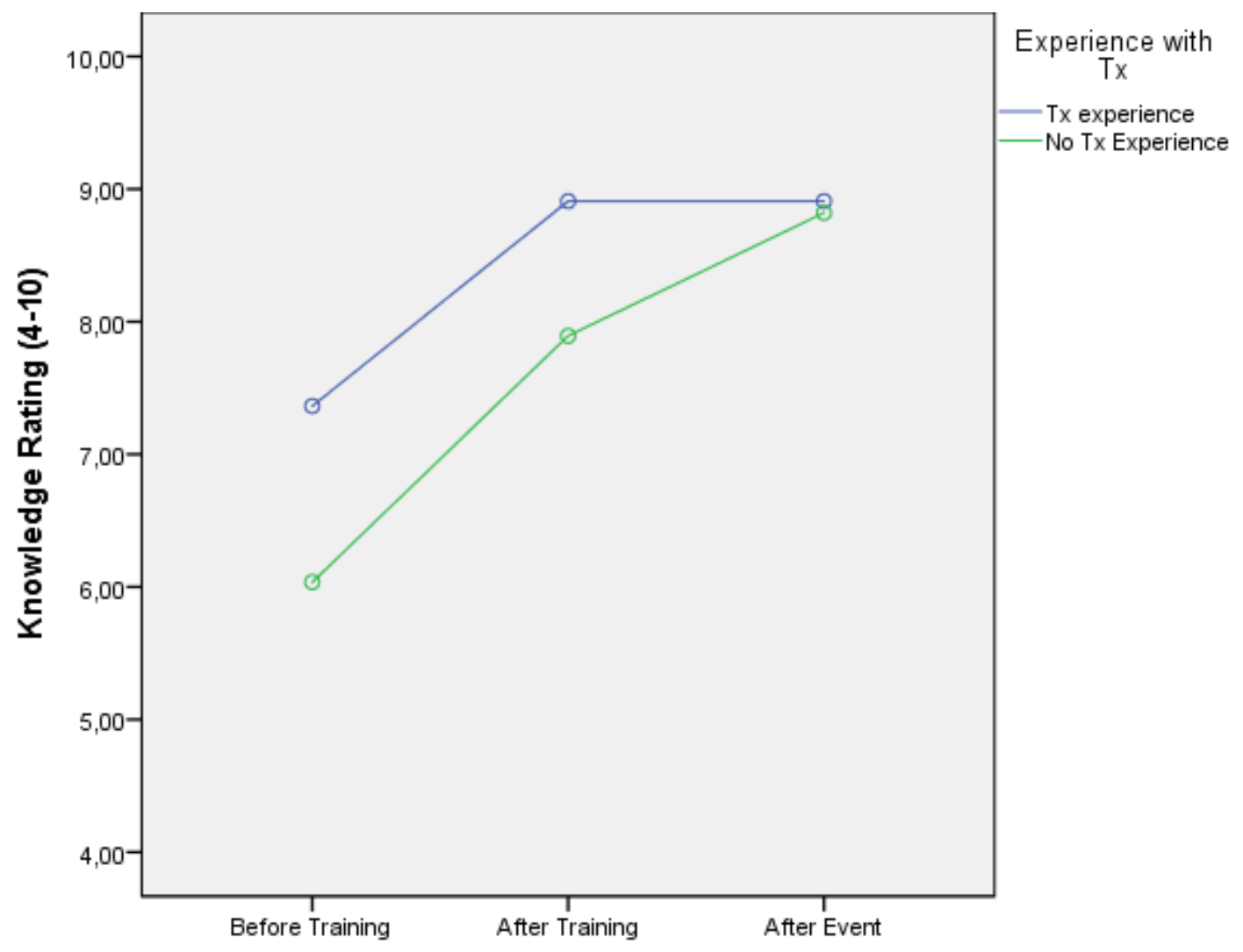

Figure 2. Changes in knowledge rating (mean scores) by groups

Metsäranta, 2006) and Gymnastics (Laitila, Ratilainen, Puronaho, \& Virkkunen, 2015), the episodic volunteers in our study were the largely opposite - older people. Skirstad and Hanstad (2013) reported young volunteers have ad hoc volunteerism at sport events and especially young women were in the majority of supportive volunteers in the 2010 Nordic Skiing World Championships. According to the results it seems that sport events for disabled or people with special needs attract older and more experienced volunteers (Khoo \& Engelhorn, 2011; Surujlal, 2010), as working with people with disabilities may require more knowledge and special skills. Younger people may feel insecure about their skills and may therefore hesitate to volunteer. Studies that have investigated on the motives for young people's mass event volunteers have included the appeal of international sports and affiliation to the event (Cuskelly et al., 2006). In the case of the Transplant sports events, the lack of media attention may have not attracted the typical young volunteer. This was exemplified by the number of Roadshows in the Helsinki Metropol area that took place during the week (Julin \& Karhu, 2016) to raise awareness of transplantation and adapted sports.

Another way to recruit volunteers of young people is to use a volunteer career profile. The FSAPD recognise the need to recruit, retain and reward their volunteers and in 2013 volunteers were kept in a volunteer database list. As part of their work as the national sport umbrella association, the FSAPD is in a good position to bring various disability groups together and encourage them to cross the traditional disability-specific borders. As such, it is likely to have encouraged more people with disabilities to take part in volunteering at ETSW than what may be typical for other sport events. The FSAPD also regards inclusion of sports as an opportunity to fulfil individual's potential in sports and that may include an athlete or other type of participation, including volunteering. The management of volunteers therefore requires a system that can adapt volunteering opportunities for individuals in a database, which may make the experience of volunteering more rewarding for persons with disabilities. Based on the social learning experiences the volunteer career profile can evolve.

None the less, the potential to involve older volunteers in other activities is one of the key components for regular volunteering at the sport club level. Previous research has found that long-term volunteers working for the sport clubs are aging in Finland (Koski, 2012; Koski \& Mäenpää, 2018) and for some volunteers who 
had no previous experience of sports volunteering, taking part in a sports event can be a gateway for future volunteering. Older people are less likely to volunteer than their younger counterparts are. However, of those who do volunteer, they are more committed to their volunteer activities than people in other age groups (Anderson et al., 2014; Official Statistics of Finland, 2009). In Finland, older people (aged 65+) are increasing in sports club volunteering compared to the other age groups (Official Statistics of Finland, 2009). Also volunteering in later life is associated with significant psychosocial, cognitive, and functional benefits for healthy older adults (Anderson et al., 2014). The possibility of engaging new volunteers for future events is important for organisations that organise multiple sports events.

Another recognised way of keeping the motives for sports event volunteering is to encourage regular sports club volunteering. Multi-sports events can raise interest, participation and volunteering in sport (Downward \& Ralston, 2006). This may be particularly important for older volunteers, or people who are retired. For the case of volunteers at the ETSW, the older people formed the majority of the volunteers which are not anymore career oriented (external/instrumental motives like CV) like young people, especially women (Downward \& Ralston, 2005). Social encounters through volunteering and having an active role in society can provide important meaning to the older person's life (Pushkar, Reis, \& Morros, 2002), and through this is an non-formalised learning through interaction and activity.

The findings of the survey suggest that volunteer training was also beneficial for the participants, both with and without prior experience to transplantation. Distinctive training concerning handling of transplantation was also necessary. In previous transplantation games, there have been fatalities. Whereas, to the researchers' knowledge, fortunately there was none at this event. Volunteers were trained in what to do in circumstances where they might be able to prevent or cope with deaths of athletes during the event. The psychological pressures that these bring may also be more suitable with mature volunteers than younger people with less life experiences. Training was structured in a way whereby a positive atmosphere (Wicker \& Hallmann, 2013) would be created as well as specifically meaningful by helping athletes, signposting the public around the sport venues, as well as some of soft skills needed for social functioning (Doherty, 2009) . Skirstad \& Hanstad (2013) mentioned there must be a balance between the sport specific skills and the support functions such as transportation, media management and spectator service. These attitudinal outlooks seem to be important for making the sports event a positive experience, especially when people visit the games from the outside (Smith \& Fox, 2007). One aim of the event was to increase awareness of organ transplants and transplant recipients (Julin \& Karhu, 2016). As such, it is likely that volunteers were actively involved in discussing transplantation with the public and the issues surrounding organ donor card. Through conversation, the volunteers had opportunities to gain reciprocal experience and knowledge in the area of transplantation. According to self-efficacy theory, these experiences would increase a persons' confidence to work with people with organ transplants. As volunteers' knowledge of the organ transplant sport had increased significantly due to the volunteer training and working at the event, it can be noted that the volunteer programme was successful in terms of achieving the goal.

The findings from this study would need to be replicated and followed up through longitudinal designs (Aisbett, Randle, \& Kappelides, 2015). Knowledge can be temporal, and the effects from volunteering experiences may be insightful for future volunteer recruitment strategies. The FSAPD uses their volunteer career model for future events. Earlier efforts to recruit, train, and maintain volunteer from outside the organization can be resource heavy (Cuskelly et al., 2006). With a career model, the returning episodic volunteers are familiar with the organisational models and the people around them. Hence, the training could be more targeted to the specific event rather than repeated general introductions. The time burden for attending training may dissuade potential volunteers who may otherwise be willing to volunteer throughout the event. A balance between training the soft skills for new volunteers as well as the core content from sports events can be challenging for event organisers (Ferrand \& Skirstad, 2015; Skirstad \& Hanstad, 2013).

There are some limitations with regards to the interpretation of the results. We did not report whether volunteers had family or friends with organ transplants. The volunteers did not complete any objective test of knowledge and provided their own perceived knowledge of transplant sports. The items were taken in retrospect and some recall inaccuracies or bias may have been reported. Only the non-competition volunteers 
were included in the survey, and sport specific volunteers from sports competition were not included, thus limiting the scope of the findings to the non-competition event volunteers.

\section{Perspective}

This study provides an insight into the management of supportive volunteers of adapted sports events by examining the training of volunteers. As with the majority of competitive adapted physical activities events, volunteers are needed to help athletes and spectators. The management of volunteers from recruitment, training and retaining can be resource heavy and it is therefore important to investigate the short- and longterm effects from training. Social learning theory was used to help explain how the experience of training and participating in the European Transplant Sports Week 2016 increased knowledge of transplantation and sport among the volunteers. This theory could be applied across multiple context of Adapted Physical Activity and may be the basis of improved self-efficacy of instructors. The potential of introducing people to regular volunteering, such as sport instructing, can be through sports events

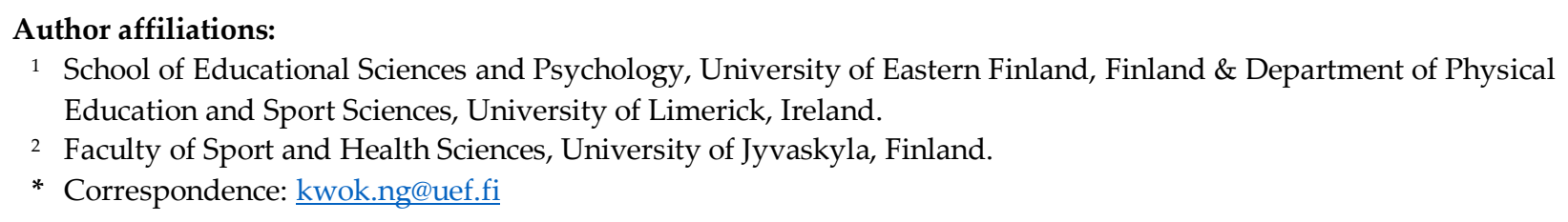

Author Contributions: KN drafted the manuscript. Conceptualization, KN \& AKS.; Methodology, KN; Formal Analysis, KN; Writing-Original Draft Preparation, KN \& AKS; Writing-Review \& Editing, KN \& AKS.

Funding: This project was co-funded by the Erasmus+ programme, project number 567168-EPP-1-2015-2-FI-SPO-SNCESE.

Acknowledgments: The European Commission support for the production of this publication does not constitute an endorsement of the contents which reflects the views only of the authors, and the Commission cannot be held responsible for any use which may be made of the information contained therein. The authors would like to acknowledge Essi Kähkönen for reviewing the manuscript and providing constructive comments, Tiina Siivonen, Volunteer Manager from the Finnish Sports Association for Persons with Disabilities (VAU in Finnish), and Aija Saari (Research Manager of VAU) who helped with the development of the questionnaire.

Conflicts of Interest: The authors declare no conflict of interest. The funders had no role in the design of the study; in the collection, analyses, or interpretation of data; in the writing of the manuscript, and in the decision to publish the results.

\section{References}

Aisbett, L., Randle, E., \& Kappelides, P. (2015). Future volunteer intentions at a major sport event. Annals of Leisure Research, 18(4), 491-509. doi:10.1080/11745398.2015.1079492

Anderson, N. D., Damianakis, T., Kröger, E., Wagner, L. M., Dawson, D. R., Binns, M. A., . . BRAVO Team. (2014). The benefits associated with volunteering among seniors: A critical review and recommendations for future research. Psychological Bulletin, 140(6), 1505-1533. doi:10.1037/a0037610

Bandura, A. (1969). Social learning of moral judgments. Journal of Personality and Social Psychology, 11(3), $275-279$. doi:10.1037/h0026998

Bandura, A. (1977). Self-efficacy: Toward a unifying theory of behavioral change. Psychological Review, 84(2), $191-215$. doi:10.1016/0146-6402(78)90002-4

Cohen, J., \& Cohen, P. (1975). Applied multiple regression/correlation analysis for the behavioral sciences. Oxford, England: Lawrence Erlbaum, Oxford.

Cuskelly, G., Taylor, T., Hoye, R., \& Darcy, S. (2006). Volunteer management practices and volunteer retention: A human resource management approach. Sport Management Review, 9(2), 141-163. doi:10.1016/S1441-3523(06)70023-7

Doherty, A. (2009). The volunteer legacy of a major sport event. Journal of Policy Research in Tourism, Leisure and Events, 1(3), 185-207. doi:10.1080/19407960903204356

Downward, P., \& Ralston, R. (2005). Volunteer motivation and expectations prior to the XV commonwealth games in manchester, UK. Tourism and Hospitality Planning \& Development, 2(1), 17-26. doi:10.1080/14790530500072310

Downward, P., \& Ralston, R. (2006). The sports development potential of sports event volunteering: Insights from the XVII manchester commonwealth games. European Sport Management Quarterly, 6(4), 333-351. doi:10.1080/16184740601154474

Fairley, S., Kellett, P., \& Green, B. C. (2007). Volunteering abroad: Motives for travel to volunteer at the Athens Olympic games. Journal of Sport Management, 21(1), 41-57. doi:10.1123/jsm.21.1.41 
Farrell, J. M., Johnston, M. E., \& Twynam, D. G. (1998). Volunteer motivation, satisfaction, and management at an elite sporting competition. Journal of Sport Management, 12, 288-300. doi:10.1123/jsm.12.4.288

Ferrand, A., \& Skirstad, B. (2015). The volunteers' perspective. In M. M. Parent, \& J. Chappelet (Eds.), Routledge handbook of sports event management (pp. 65-88). Abingdon, Oxon: Routledge.

Finnish National Agency for Education. (2018). Pupil and student assessment. Retrieved from http://www03.oph.fi/sanasto/alaluokka3 3.asp

Giannoulakis, C., Wang, C., \& Gray, D. (2007). Measuring volunteer motivation in mega-sporting events. Event Management, 11(4), 191-200. doi:10.3727/152599508785899884

Grusec, J. E. (1992). Social learning theory and developmental psychology: The legacies of Robert Sears and Albert Bandura. Developmental Psychology, 28(5), 776-786.

Hutzler, Y., \& Hellerstein, D. (2016). Adapted versus adaptive physical activity. Adapted Physical Activity Quarterly, 33(2), 109-112. doi:10.1123/APAQ.2016-0027

Itkonen, H., Ilmanen, K., Lämsä, J., Matilainen, P., \& Metsäranta, O. (2006). Elämyksiä ja yhteisöllisyyttä etsimässä: MMkisojen vaikutus liikunnan kansalaistoimintaan [Searching for experiences and sense of community: Effect of the World Championships in civic activity]. In M. Nylund, S. Laakso \& S. Ojajärvi (Eds.), Urheilu, maine ja raha. tutkimuksia vuoden 2005 yleisurheilun MM-kisoista [sports, reputation and money. studies of the 2005 world athletics championships] (pp. 47-71). Helsinki: Gaudeamus.

Julin, M., \& Karhu, I. (2016). European transplant sport week 2016 - evaluation report. (Evaluation Report). Helsinki: Suomen Vammaisurheilu ja liikunta VAU ry. Retrieved from http://ec.europa.eu/programmes/erasmus-plus/projects/eplusproject-details/\#project/8169a540-4761-40a5-ab7b-bed5b859789b

Khoo, S., \& Engelhorn, R. (2011). Volunteer motivations at a national Special Olympics event. Adapted Physical Activity Quarterly, 28(1), 27-39. doi:10.1123/apaq.28.1.27

Klein, N. A., \& Sondag, K. A. (1994). Understanding volunteer peer health educators' motivations: Applying social learning theory. Journal of American College Health, 43(3), 126-130. doi:10.1080/07448481.1994.9939096

Koski, P. (2012). Finnish sports club as a mirror of society. International Journal of Sport Policy and Politics, 4(2), $257-275$. doi:10.1080/19406940.2012.656852

Koski, P., \& Mäenpää, P. (2018). Suomalaiset liikunta- ja urheiluseurat muutoksessa 1986-2016 [Transition of Finnish sports clubs in 1986-2016]. (No. 25). Helsinki: Publications of the Ministry of Education and Culture. Retrieved from http://urn.fi/URN:ISBN:978-952-263-575-4

Laitila, O., Ratilainen, T., Puronaho, K., \& Virkkunen, K. (2015). Gymnaestrada 2015 Helsinki - event research. (No. 6). Helsinki: Valtion Liikuntaneuvoston Julkaisuja.

Lund, L. H., Edwards, L. B., Kucheryavaya, A. Y., Benden, C., Christie, J. D., Dipchand, A. I., . . Stehlik, J. (2014). The registry of the international society for heart and lung transplantation: Thirty-first official adult heart transplant Report-2014; focus theme: Retransplantation. The Journal of Heart and Lung Transplantation, 33(10), 996-1008. doi:10.1016/j.healun.2014.08.003

Mathou, C. (2010). Study on volunteering in the European Union - final report. Brussels: GHK. Retrieved from http://ec.europa.eu/citizenship/pdf/doc1018 en.pdf

Official Statistics of Finland. (2009). Time use survey. participation and volunteer work 2009. (e-publication). Helsinki: Statistics Finland.

Preuss, H. (2006). The economics of staging the Olympics; A comparison of the games 1972-2008. Cheltenham, Glous.: Edward Elgar Publishing.

Pushkar, D., Reis, M., \& Morros, M. (2002). Motivation, personality and well-being in older volunteers. The International Journal of Aging and Human Development, 55(2), 141-162. doi:10.2190/MR79-J7JA-CCX5-U4GQ

Rantalainen, E., \& Taskinen, I. (2015). Volunteer management in sport event case: Gymnaestrada Helsinki 2015. (Unpublished BSc). Jyvaskyla University of Applied Sciences, Jyväskylä. Retrieved from https://www.theseus.fi/bitstream/handle/10024/109800/Opinn\%C3\%A4ytety\%C3\%B6 Taskinen Rantalainen.pdf

Shiota, K. (2018). Survey report on awareness and participation behavior in disabled sports and disability understanding after tokyo's bid for the 2020 Olympics and Paralympics. Journal of Physical Therapy Science, 30(1), 5-10. doi:10.1589/jpts.30.5

Skirstad, B., \& Hanstad, D. V. (2013). Gender matters in sport event volunteering. Managing Leisure, 18(4), 316-330.

Smith, A., \& Fox, T. (2007). From 'event-led' to 'event-themed' regeneration: The 2002 Commonwealth Games legacy programme. Urban Studies, 44(5-6), 1125-1143. doi:10.1080/00420980701256039

Surujlal, J. (2010). Volunteer motivation in special events for people with disabilities. African Journal for Physical, Health Education, Recreation and Dance, 16, 460-474.

Tufts, S. (2004). Building the 'competitive city': Labour and Toronto's bid to host the Olympic games. Geoforum, 35(1), 4758. doi:10.1016/j.geoforum.2003.01.001 
Convention on the rights of persons with disabilities and optional protocol, A/RES/61/106, (2006). Retrieved from https://www.un.org/disabilities/documents/convention/convoptprot-e.pdf

van Adrichem, E. J., van de Zande, S. C., Dekker, R., Verschuuren, E. A. M., Dijkstra, P. U., \& van der Schans, C. P. (2016). Perceived barriers to and facilitators of physical activity in recipients of solid organ transplantation, a qualitative study. PLoS ONE, 11(9), e0162725. doi:10.1371/journal.pone.0162725

Wicker, P., \& Hallmann, K. (2013). A multi-level framework for investigating the engagement of sport volunteers. European Sport Management Quarterly, 13(1), 110-139. doi:10.1080/16184742.2012.744768

Williams, T. J., \& McKenna, M. J. (2012). Exercise limitation following transplantation. Comprehensive Physiology, 2, 19371979. doi:10.1002/cphy.c110021

Zimbalist, A. (2016). Circus maximus: The economic gamble behind hosting the Olympics and the World Cup (2nd ed.). Washington D.C.: Brookings Institution Press.

(C) 2019 by the authors. Submitted for possible open access publication under the terms and conditions of the Creative Commons Attribution (CC BY) license (http://creativecommons.org/licenses/by/4.0/). 